\title{
Assessment of wind power Potential at Zeway, Central Rift Valley
}

\author{
G.Ashenafi Tolessa \\ Department of Agricultural Engineering, Adama Science and Technology University, 1888, Adama, Ethiopia
}

\begin{abstract}
Wind is one of the renewable resources in Zeway which is unexploited. This paper presents a number of issues related to the Assessment of wind energy resource based on 16 years long-term measured data of daily wind speed and direction, 3-hourly measured wind data at $10 \mathrm{~m}$ height, which are obtained from meteorological station and Analysis carried out By using Rayleigh stastical Analysis for wind data analysis and Matlab software used for data acquisition. This study indicates that Zeway, has energy potential available with the maximum and minimum average wind speed respectively, $4.9 \mathrm{~m} / \mathrm{s}$ and $1.5 \mathrm{~m} / \mathrm{s}$ and average wind power density also varies with maximum and minimum values respectively, $68.6 \mathrm{w} / \mathrm{m}^{2}$ and $0.0 \mathrm{w} / \mathrm{m}^{2}$ and the Results suggested that wind energy must be encouraged, promoted, invested, implemented, and demonstrated, but especially for small Wind farm.
\end{abstract}

Key Words- wind speed and direction, Rayleigh probability density, power density, wind speed probability curve, Zeway.

\section{INTRODUCTION}

Motion in air is a vector; as such it has both direction and speed. The broad movement of masses of air across the global, linking together continent and defying international boundaries might be singled out as the dominant variable of the atmosphere, producing pattern and ensembles of weather and climate. Most of the time we fell about large revolving storms and great waves of the upper air may travel from one place to the other. The climate of one region is totally different than other, depending on whether the wind blows onshore or offshore. it is partly the winds that divide the world's atmosphere into two main parts; the tropics, with winds blowing steadily from the east called trade winds and the belts beyond latitude $30^{\circ} \mathrm{N}$ and $30^{\circ} \mathrm{S}$, with winds from the west that keep shifting direction and speed from day to day and bring changeable weather [4].

The wind is free, clean and inexhaustible source of energy. The winds of the earth are caused primarily be unequal heating of the earth's surface by the sun. The earth extracts energy from the sun and delivers heat to space which is at lower temperature [3]. In this process, work is done on the gases in the atmosphere and on the earth-atmosphere boundary. There will be regions where the air pressure is temporarily higher or lower than an average. This difference in the air pressure causes atmospheric gases or wind flow from the region of higher pressure to that of lower.

Ethiopia has immense potential of renewable and non-renewable energy resources. The exploitable reserve potential of renewable resources such as biomass, solar, wind and geothermal energies is estimated to be $1,383,7,432,901$ and 12 thousand of TJ respectively. The non-renewable exploitable potential resources such as coal and natural gas are estimated to be about 13.7 million tons and 160 billion $\mathrm{m}^{3}$, respectively. However, except biomass, which has been over-exploited for several years in its traditional form, most of the country energy resources have not been adequately assessed and have not yet been tapped [ http:// www.regionalenergy-net.com]

Excluding human and animal energy, the source of energy supply of Ethiopia can be categorized into traditional and modern energy sources. Traditional energy supply is dominated by biomass which consists of fuel wood, agriculture residue, charcoal and cattle and accounts for about $94.71 \%$ of the total energy supply wherein fuel wood is the dominant source of supply. The sources of modern energy supply are petroleum and electricity, and the former accounts for $87 \%$ of Ethiopia's modern energy consumption. Electricity accounts for the remaining $13 \%$ of which large hydro covers about $97.8 \%$ of electricity supply. The country's energy consumption is also dominated by biomass, which accounts for about $96.28 \%$ while the share of petroleum and electricity is $3.32 \%$ and $0.41 \%$, respectively. The major energy consumer of the country is the household sector constituting about $93.53 \%$ of the total national energy consumption [http:// www.regionalenergynet.com].

Different studies indicate that Ethiopia is endowed with substantial renewable energy resources. A hydropower resource suitable for small-scale hydropower includes Pico/micro estimated to be about 26 to 38 times the existing power supply of the country. The solar potential of the country is also massive and can satisfy the future energy supply need of the country for several years. The identified geothermal potential that can be used to generate electric power is estimated to be about $700 \mathrm{MW}$ to 3,000 MW, which is again much larger than 
the existing power supply of the country. Assessments carried out in four sugar factories of the country indicated that electric energy generated by cogeneration can be exported to the national grid or isolated grids in addition to meeting sugar factory power and heat requirements. However, due to shortage of finance, policy issues, lack of awareness of renewable energy users and developers, inadequacy of energy institutions and other related barriers, renewable energy resources of the country have not been used to fuel socio-economic development of the nation. As a result, rural Ethiopians, which account for about $85 \%$ of the total population of the country, lack modern energy services [ http:// www.regionalenergy-net.com].

In order to use the wind energy in the study area, determination of available wind resource is critically important. Quantification of wind pattern of wind potential is useful for policy makers to distribute the available resource in terms of local demand and improve the community awareness for the application of alternate energy. This study was designed to explore winds that could contribute towards the development of alternative energy by assessing the wind power and the potential contribution of wind for different application.

\subsection{Location and Topography of the study area}

\section{MATERIALS AND MethodS}

Ziway is a town in central Ethiopia. It is located on the road connecting Addis Ababa to Nairobi in the Misraq Shewa Zone of the Oromia Region of Ethiopia, Ziway has a latitude and longitude of $7^{\circ} 56^{\prime} \mathrm{N} 38^{\circ} 43^{\prime} \mathrm{E} /$ $7.933^{\circ} \mathrm{N} 38.717^{\circ} \mathrm{E} / 7.933 ; 38.717$ with an elevation of 1643 meters above sea level [http://en.wikipedia.org/wiki/Wind_power].

Adjacent to Lake Ziway, the economy of the town is based on fishing and horticulture. Ziway is also home to a prison and a caustic soda factory.

\subsection{Data collection}

Consideration has been given to the consistent and effective presentation of data. Original data were extracted from National Meteorological Agency (NMA) Zeway station recorded the relative data available on wind speed and direction. Wind energy data consists of mean monthly wind speeds and wind directions measured at a height of $10 \mathrm{~m}$ above ground from stations. Relatively accurate and properly maintained anemometers collected data. The stations, recording period was greater than 10 year and average recording intervals of an hour were satisfactory. Monthly wind speed frequency distribution was also tabulated. The major parameter affecting the accuracy of the data was the exposure of the recording equipment to climate conditions. These data were utilized to determine annual wind speed frequency distribution, a major parameter in computing wind power density at a given site.

Generally, all wind speed and direction data of this work were collected from the meteorological observatories of the National Meteorological Agency (NMA); where 3-cup anemometers with $127 \mathrm{~mm}$ diameter conical cups and wind-run-counter anemometers, in conformity with international practice, are used. Anemometers at different meteorological stations are normally at $10 \mathrm{~m}$ height, but if at a different height the data are adjusted to $10 \mathrm{~m}$ by the NMA according to methods of the World Meteorological Organization (WMO) [9]. Wind energy and its characteristics have been studied based on secondary wind speed and direction data available which is measured and collected by NMA at Zeway, CRV.The data collected from Zeway station are obtained at wind-run-counter cup heights of 10 meters and the wind measurements are taken every three hours a day (i.e. 06, 09,12,15,18 LST). The agency has different kinds of stations (principal, $3^{\text {rd }}, 2^{\text {nd }}, 1^{\text {st }}$ class) over the country, the principal station which is vulnerable with wind speeds and direction record at 10 meters are mostly available at airports.

\subsection{Wind data refinement}

All data are reviewed for accuracy and invalid data are removed to create a validated data set which implies all data checking and processing has been done. As per the data, the study period is going to be from 1989 to 2004. Perhaps, 16 years of Data has been used. Data Checking for all the records are inter correctly over the study period can be done by running all the archive data into the excel software application (i.e. (Row1) $/ 12=$ Ans, in Ziway Data $(193-1) / 12=16,16$ or $[($ Final year - Initial year $)+1]=[$ Row -1$]$ i.e. $[(2004-1989)$ $+1]=[193-1]$ is an integer so it is inter correctly.

As per the data gap, 16 years of data has obtained. i.e. from 1989 - 2004 from which year 1991,1994,2001 and 2002 are missing(unrecorded) year, Through the study period 4 leap years (i.e. the month February become 29 which make the number of days in the year become 366 instead of $365(\mathrm{Feb=29,366)})$ and 11 normal year $(\mathrm{Feb}=28,365)$, in leap year 6 days of unrecorded data has been obtain by assuming every month has 31 days so that [6* 4 leap years] is going to be 24 and over normal years 7 days of unrecorded data so that [7 * 11 normal years] is going to be 77 days. Total unrecorded data is going to be $(77+24)=101$ days.

Total number of recorded data is $([($ Row -1$) * 31]($ i.e. $[(193-1) * 31])$ going to be $(5952-101)=5851$ days. There fore, 5851days records should be achieved but it gives 4343 days records because of the data gaps. The ratio 
between the recorded data to total data in the study period has to bring $(4343 / 5851=0.74 * 100)=74.22 \%$ so the deficit is $(100-74.22)=25.77 \%$

Generally, there is $25.77 \%$ data gap which occurs due to various reasons such as failures of data logger officer (i.e. due to out time recording, personal problem or other weather phenomenon), data transportation between the station and head office of the NMA data server, etc. So base on this data we develop the Matlab program to refine the extreme data with the average mean data with this 16 year data.

It is customary to average the wind speeds during each hour and use the hourly mean wind speed as the basic parameter in calculations of wind power [16].In this study, the relationships between annual mean wind speed (at anemometer height of $10 \mathrm{~m}$ ) and potential of the wind energy is evaluated based on the data available at Zeway.

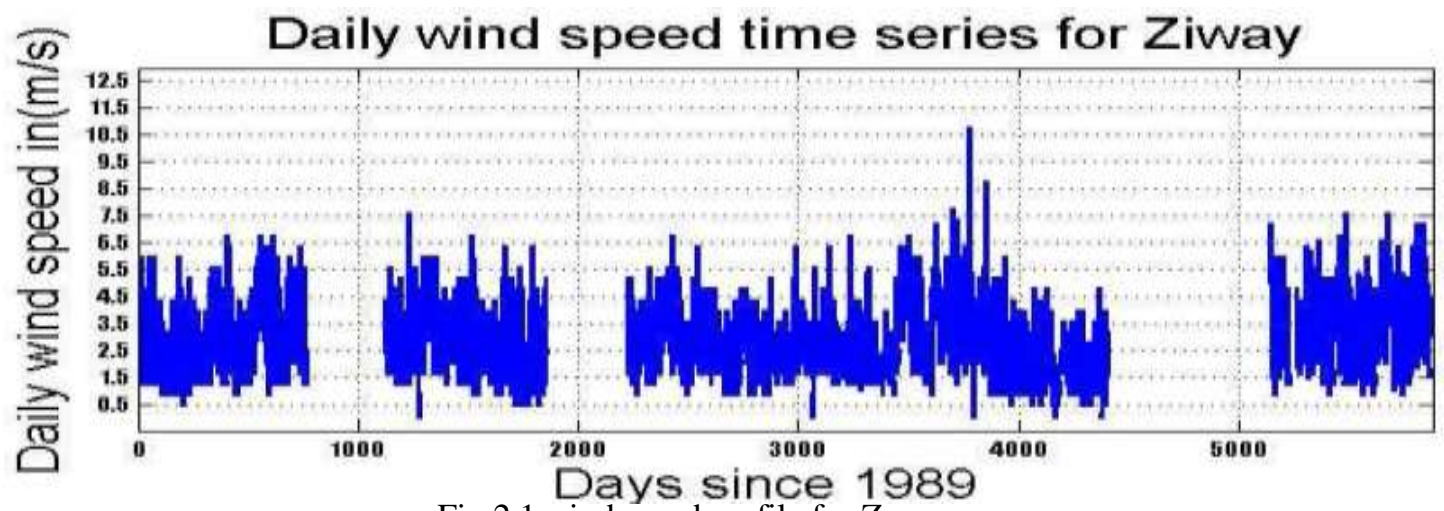

Fig.2.1 wind speed profile for Zeway

In studying wind data in relation to the generation of mechanical energy by wind power MATLAB 7.0 was used to present daily, monthly and annual average wind speed of, Zeway, CRV in terms of wind speed and direction and emphases that considerable case is taken in the assessment of local wind power potential from available 16 years wind records taken from National Meteorology Agency (NMA) .

\subsection{Wind statistics}

Wind is highly variable power source and there are several methods of characterizing this variability. Most common is the power duration curve [4], [7]. Another method is to use a statistical representation, particularly Weibull probability function.

\subsection{Weilbull distribution}

Sher Mohammad Nasir [8] describes the important family of continuous distributions which have been used to model the variability of non-negative random phenomena in the family of weibull distribution named after the Swedish physicist wallodi weibull.

A random variable $\mathrm{V}$ has a weibull distribution if its probability density function and cumulative distribution function [1] has following forms:

$$
\begin{gathered}
\mathrm{f}(\mathrm{v})=\mathrm{k} / \mathrm{C}(\mathrm{V} / \mathrm{C})^{\mathrm{K}-1} \exp \left[-(\mathrm{V} / \mathrm{C})^{\mathrm{K}}\right] \\
\mathrm{F}(\mathrm{V})=1-\exp \left[-(\mathrm{V} / \mathrm{C})^{\mathrm{K}}\right] ;(\mathrm{K}>0, \mathrm{~V}>0, \mathrm{C}>0)
\end{gathered}
$$

Where $\mathrm{C}$ is scale and $\mathrm{K}$ is shape parameters, respectively.

The weibull distribution is a two parameter distribution; this makes the distribution some- what more versatile and simple to use.The two parametric weibull function provides an empirical method for accurate representation of wind distributions. if the scale parameter is equal to 1 , than the weibull distribution reduces to that of the negative exponential distribution; so the probability density function of the standard weibull distribution reduces to that of the negative exponential distribution; so the probability density function of the standard weibull distribution which depends only on a single parameter $\mathrm{k}$ is given as below after substituting $\mathrm{C}=$ 1 in equation (3).

$$
\mathrm{F}(\mathrm{V})=\mathrm{K}^{*} \mathrm{~V}^{\mathrm{K}-1} \exp (-\mathrm{V})^{\mathrm{K}} ; \mathrm{V}>0, \mathrm{~K}>0
$$

\subsection{Rayleigh distribution}

There are several density functions which can be used to describe the wind speed frequency curves. The second most important continuous distribution is the rayleigh distribution. Statistically this distribution is a 
subset of weibull distribution with shape parameter $\mathrm{K}=2$ and is often sufficiently accurate for analysis of wind statistics at a given site. The Raleigh probability density function is given by [5]:

$$
\mathrm{f}(\mathrm{V})=\pi \mathrm{V}_{\mathrm{i}} / 2 \mathrm{~V}_{\mathrm{m}}^{2} \exp \left[-\pi / 4\left(\mathrm{~V}_{\mathrm{i}} / \mathrm{V}_{\mathrm{m}}\right)^{2}\right]
$$

But the rayleigh cumulative distribution function is:

where $\mathrm{V}_{\mathrm{m}}$ is mean of the wind speed.

$$
\mathrm{f}(\mathrm{V})=1-\exp \left[-\pi / 4\left(\mathrm{~V}_{\mathrm{i}} / \mathrm{V}_{\mathrm{m}}\right)^{2}\right]
$$

\subsection{Wind speed duration curves}

To determine accurately the potential annual energy output of particular wind energy conversion systems (WECS) at a particular site, it is necessary to have an access to the wind speed duration curves for that site(s). I have just explained that the wind stream at a site attains a specified hourly mean wind speed and are known as average wind speed duration curves. These curves give the total number of hours per month and per year.

The speed duration curves could be used to determine the number of hours of operation of specific wind machines. These curves do not lead themselves to many features of wind machines / turbines design or selection, because it is difficult to determine the optimum rated wind speed or average power output from speed duration curves.

\subsection{Wind Speed frequency curves}

The frequency of occurrence of wind speed is essential in assessing the energy potential of a given site. The annual frequency distribution curve shows the number of hour for which the wind speed of a particular magnitude existed. The summation of the number of hours at each speed over all the wind speed intervals should be the total number of hours in the year. These curves have some important features [8]:

1. The intercept on the vertical axis is always greater than zero due to the existence of calm spells at any site.

2. The most frequent speed is lower than the mean wind speed and varies with it and

3. The most frequent speed or the peak of the curve decreases. If we know the wind speed $\mathrm{v}$ existed for $\mathrm{t}$ (hours) during the year than the energy available for that wind speed is :

$$
\mathrm{E}_{\mathrm{i}=} \mathrm{P}_{\mathrm{i}} * \mathrm{t}_{\mathrm{i}}
$$

\subsection{Wind power Analysis}

The wind has a power to make the rotor rotate .The amount of energy (power) which can be extracted from the wind is equivalent to the area swept by the rotor, the velocity of the wind (when the wind speed is increasing the rotor is able to turn faster) and the density of the wind. (The power in the wind is proportional to the cube of wind velocity [2]

The general formula for wind Power is:

Where:

$$
P_{\text {wind }}=\rho^{*} v^{3 *} A
$$

$\mathrm{P}_{\text {wind }}$ is the power in the wind in Watts

$\rho$ is the density of the air in $\mathrm{kg} / \mathrm{m}^{3}$

$\mathrm{V}$ is the speed of the wind in $\mathrm{m} / \mathrm{s}$

A area which is covered by the rotor in $\mathrm{m}^{2}$

This means that the power density in the wind will range from $10 \mathrm{~W} / \mathrm{m}^{2}$ at $2.5 \mathrm{~m} / \mathrm{s}$ (a light breeze) to $41,000 \mathrm{~W} / \mathrm{m}^{2}$ at $40 \mathrm{~m} / \mathrm{s}$ (a hurricane). This variability of the wind power resource strongly influences virtually all aspects of wind energy conversion systems design, construction, siting, use and economy.

\section{RESULTS AND DISCUSSIONS}

It is very difficult to make broad generalization about the wind speed variation but the researcher can take discussion on hourly, monthly and annual Wind data distribution individually. Hence hourly Rayleigh probability curves show very good Amplitude at $2 \mathrm{~m} / \mathrm{s}$ and longer span for lower wind speeds. The graphs give the peak is sharp when average wind speed is $2.0 \mathrm{~m} / \mathrm{s}$ and a flatter shape when the mean of the wind speed is lower. monthly Raleigh probability curves show very good Amplitude at $2 \mathrm{~m} / \mathrm{s}$ and longer span for higher wind speeds. The graphs give the peak is sharp when average wind speed is $2.0 \mathrm{~m} / \mathrm{s}$ and a flatter shape when the mean of the wind speed is higher. The annual Raleigh probability curves show very good Amplitude at $2.5 \mathrm{~m} / \mathrm{s}$ and longer span for higher wind speeds. The graphs give the peak when average wind speed is $2.5 \mathrm{~m} / \mathrm{s}$ and a flatter shape when the mean of the wind speed is higher.

The speed duration curve are derived from the wind speed graph based on the 3-hourly averaged data for Zeway. The horizontal axis is in hours per year, with a maximum value of 700 and 900 for a year. The 
vertical axis gives the wind speed that is exceeded for the number of hours per year on the horizontal axis. Wind speed of $2 \mathrm{~m} / \mathrm{s}, 3 \mathrm{~m} / \mathrm{s}$ and so on, exceeded number of hours per year are given in table: 5.1. Considering table 5.1 we observed that the minimum annual duration for wind speeds exceeding $4 \mathrm{~m} / \mathrm{s}$, exists in year 1996, 1998 and 2000 For a speed of up to $2 \mathrm{~m} / \mathrm{s}$ varies from $0-360 \mathrm{hrs}$.

Table 3.1 Annual frequency of wind speed $(\mathrm{m} / \mathrm{s})$ and number hours during a year.

\begin{tabular}{|l|c|c|c|c|}
\hline $\begin{array}{l}\text { Study } \\
\text { year }\end{array}$ & $\begin{array}{l}\text { Wind speed } \\
\text { when V=2 m/s }\end{array}$ & $\begin{array}{l}\text { Wind speed } \\
\text { when V=3 m/s }\end{array}$ & $\begin{array}{l}\text { Wind speed } \\
\text { when V=4 m/s }\end{array}$ & Peak value wind speed m/s (hrs) \\
\hline 1989 & 270 & 540 & 270 & $3(540)$ \\
\hline 1990 & 90 & 270 & 540 & $4(540)$ \\
\hline 1992 & 0 & 360 & 630 & $4(630)$ \\
\hline 1993 & 0 & 810 & 270 & $3(810)$ \\
\hline 1995 & 0 & 450 & 630 & $4(630)$ \\
\hline 1996 & 270 & 720 & 90 & $3(720)$ \\
\hline 1997 & 0 & 900 & 180 & $3(900)$ \\
\hline 1998 & 180 & 270 & 90 & $3(270)$ \\
\hline 1999 & 0 & 540 & 360 & $3(640)$ \\
\hline 2000 & 360 & 630 & 90 & $4(720)$ \\
\hline 2003 & 0 & 270 & 720 & $4(630)$ \\
\hline 2004 & 0 & 270 & 630 & \\
\hline
\end{tabular}

The wind speed frequency curves give the number of hours per year that the wind speed is in $1 \mathrm{~m} / \mathrm{s}$ interval. One can see from figures that the largest time of calm spells occurred at 06:00 Am in the morning and the shortest time of calm spell at 18:00 PM in the evening.

For any wind energy system the frequency of occurrence of usable wind speed is very important. The wind speed of approximately $3 \mathrm{~m} / \mathrm{s}$ which is considered us the rating velocity of any wind machine is hereby shown from the speed frequency curves as shown in table 4.2. From these curve the most frequent wind speed i.e. the peak value of each curve and its duration are also shown in table 4.2.

Table: 3.2 data corresponding to wind speed frequency curves.

\begin{tabular}{|c|c|c|}
\hline Study year & $\begin{array}{l}\text { Most Frequent Wind } \\
\text { speed }(\mathrm{m} / \mathrm{s})\end{array}$ & $\begin{array}{l}\text { Average wind speed } \\
(\mathrm{m} / \mathrm{s})\end{array}$ \\
\hline 1989 & 3 & 3 \\
\hline 1990 & 4 & 3 \\
\hline 1992 & 4 & 3 \\
\hline 1993 & 3 & 3 \\
\hline 1995 & 4 & 3 \\
\hline 1996 & 3 & 3 \\
\hline 1997 & 3 & 3 \\
\hline 1998 & 5 & 3 \\
\hline 1999 & 3 & 2 \\
\hline 2000 & 3 & 3 \\
\hline 2003 & 4 & 3 \\
\hline 2004 & 4 & \\
\hline
\end{tabular}

The study show the diurnal wind speed patterns in Zeway for a period of 1989 - 2004.the daily peak value of wind speed occurs between 9.00 to 12.00 hours in all year and the wind speed exceeds $2.5 \mathrm{~m} / \mathrm{s}$ every day for all study year. In general the distribution for the average monthly wind speed and average wind power density shows single maximum in June and the minimum in September. The mean wind speed values at $10 \mathrm{~m}$ height are shown in Figure 4.31. It's frequency from $2.36 \mathrm{~m} / \mathrm{s}$ to $3.65 \mathrm{~m} / \mathrm{s}$, for months, September (9), June (6) respectively (i.e. the minimum value of average wind speed is in September and the maximum in June. The mean wind speed for sixteen years was $2.9 \mathrm{~m} / \mathrm{s}$, this figure shows mean wind speeds at $10 \mathrm{~m}$ heights. 


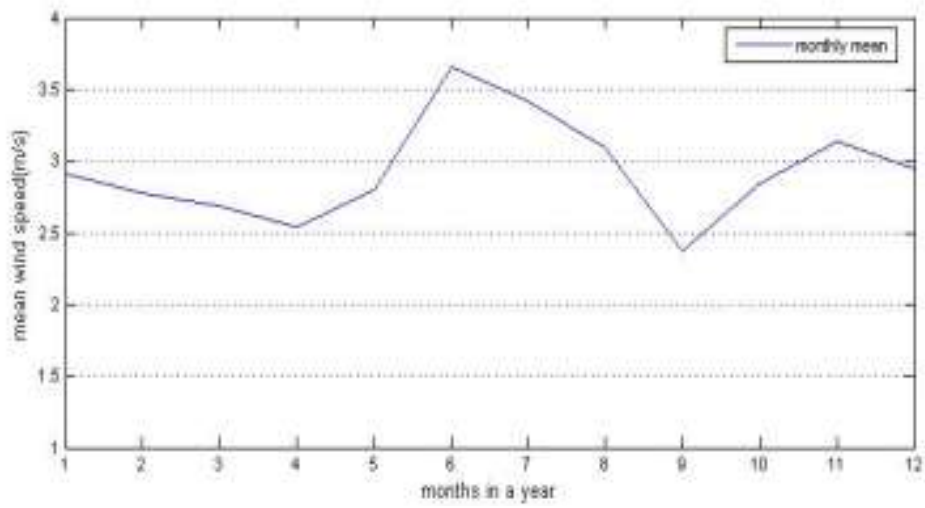

Fig.3.1 monthly mean wind speed (from Matlab)

Table3.3. monthly mean wind speed at 10 meter height in $(\mathrm{m} / \mathrm{s})$

\begin{tabular}{|l|l|l|l|l|l|l|l|l|l|l|l|l|}
\hline Months & Jan & Feb & Mar & Apr & May & Jun & Jul & Aug & Sep & Oct & Nov & Dec \\
\hline 1989 & 2.5 & 2.6 & 1.7 & 1.6 & 2.6 & 3.0 & 3.1 & 2.5 & 1.9 & 2.8 & 3.8 & 2.8 \\
\hline 1990 & 1.6 & 2.7 & 2.5 & 4.0 & 4.8 & 4.0 & 3.9 & 2.9 & 3.8 & 3.3 & 3.6 & 3.3 \\
\hline 1992 & 2.7 & 2.7 & 3.4 & 2.7 & 3.7 & 4.1 & 3.1 & 2.7 & 3.3 & 3.1 & 3.0 & 3.3 \\
\hline 1993 & 2.7 & 2.8 & 2.2 & 2.3 & 3.3 & 2.9 & 3.0 & 2.3 & 2.4 & 2.7 & 2.3 & 3.1 \\
\hline 1995 & 2.7 & 3.2 & 3.1 & 2.6 & 3.9 & 3.8 & 3.6 & 2.7 & 2.6 & 3.3 & 3.6 & 2.6 \\
\hline 1996 & 2.3 & 2.2 & 2.0 & 2.1 & 3.1 & 2.9 & 2.4 & 1.9 & 2.5 & 2.3 & 2.2 & 1.9 \\
\hline 1997 & 3.4 & 2.8 & 2.6 & 2.7 & 2.8 & 3.1 & 2.5 & 2.1 & 2.7 & 2.5 & 2.5 & 2.3 \\
\hline 1998 & 1.8 & 2.0 & 1.9 & 3.2 & 4.5 & 4.3 & 4.1 & 2.3 & 2.7 & 4.1 & 4.0 & 4.6 \\
\hline 1999 & 4.2 & 3.5 & 4.1 & 3.1 & 3.7 & 3.4 & 2.9 & 2.3 & 2.1 & 2.8 & 2.5 & 2.2 \\
\hline 2000 & 2.4 & 2.4 & 2.1 & 1.5 & 2.3 & 2.1 & 2.3 & 1.5 & 1.9 & 2.1 & 1.9 & 3.1 \\
\hline 2003 & 3.7 & 3.2 & & 3.0 & 3.9 & 3.6 & 3.4 & 2.9 & 3.5 & 3.6 & 3.4 & 2.5 \\
\hline 2004 & 3.3 & 3.0 & 2.5 & 3.8 & 4.9 & 3.8 & 3.4 & 2.9 & 3.8 & 4.1 & 3.4 & \\
\hline
\end{tabular}

The monthly power densities at 10-meters height are given in Table 4.4. This indicates that power density varies from $0.0 \mathrm{w} / \mathrm{m} 2$ to $68.6 \mathrm{w} / \mathrm{m} 2$ with a steady trend over the period from May to December.

The monthly power density of the area is $17.8 \mathrm{~W} / \mathrm{m}^{2}$, which brings the area into class-1 category of power potential (see Table 4.4). This means that in spite of high wind potential, relative to the other months, during two month (June and July) of the year, the area is suitable for low wind farms. The monthly power frequency curve is somewhat sharp and it does not show the peak point.

Table 3.4 Monthly power density $\left(\mathrm{w} / \mathrm{m}^{2}\right)$

\begin{tabular}{|l|l|l|l|l|l|l|l|l|l|l|l|l|}
\hline Months & Jan & Feb & Mar & Apr & May & Jun & Jul & Aug & Sep & Oct & Nov & Dec \\
\hline 1989 & 9.3 & 11.1 & 3.2 & 2.5 & 10.5 & 16.4 & 17.7 & 9.7 & 4.1 & 12.8 & 32.2 & 12.6 \\
\hline 1990 & 2.6 & 12.3 & 9.8 & 39.1 & 68.0 & 38.4 & 35.5 & 14.3 & 31.9 & 21.7 & 27.1 & 21.4 \\
\hline 1992 & 11.6 & 11.3 & 23.3 & 12.3 & 29.6 & 40.3 & 17.8 & 12.4 & 21.9 & 17.8 & 16.7 & 22.4 \\
\hline 1993 & 12.4 & 13.5 & 6.7 & 7.1 & 21.2 & 15.1 & 16.3 & 7.0 & 8.7 & 11.4 & 7.6 & 18.5 \\
\hline 1995 & 11.7 & 19.9 & 17.1 & 10.3 & 34.7 & 32.3 & 28.0 & 11.7 & 10.5 & 20.9 & 27.7 & 10.0 \\
\hline 1996 & 7.2 & 6.8 & 4.7 & 5.4 & 17.8 & 14.1 & 8.0 & 4.4 & 9.1 & 7.8 & 6.4 & 4.4 \\
\hline 1997 & 22.7 & 12.8 & 10.5 & 12.5 & 13.7 & 17.3 & 9.4 & 5.3 & 12.0 & 9.4 & 9.2 & 7.2 \\
\hline 1998 & 3.4 & 4.8 & 4.3 & 19.3 & 55.4 & 47.2 & 40.3 & 7.5 & 12.2 & 42.8 & 38.8 & 56.9 \\
\hline 1999 & 44.5 & 25.7 & 41.2 & 17.2 & 29.9 & 24.3 & 14.9 & 7.8 & 5.3 & 13.2 & 9.9 & 6.8 \\
\hline 2000 & 8.0 & 7.9 & 5.2 & 2.0 & 7.5 & 5.7 & 7.1 & 1.8 & 4.3 & 5.2 & 4.4 & 18.3 \\
\hline 2003 & 29.5 & 19.7 & 0.0 & 15.8 & 34.5 & 27.4 & 23.6 & 14.0 & 25.5 & 27.5 & 23.3 & 9.6 \\
\hline 2004 & 22.2 & 15.8 & 8.9 & 33.9 & 68.6 & 32.6 & 24.1 & 15.0 & 33.3 & 42.0 & 23.3 & 0.0 \\
\hline
\end{tabular}

It can be seen that the changes in the mean wind velocity with heights which can be interpolated in order to show the change in magnitude at different height; for that reason the wind speed at $20 \mathrm{~m}$ can be interpolated by 
using equations 3.1 which results with a frequency from $2.9 \mathrm{~m} / \mathrm{s}$ in April to $3.5 \mathrm{~m} / \mathrm{s}$ in November with a mean wind speeds of $3.2 \mathrm{~m} / \mathrm{s}$.

Table 3.5 mean monthly wind speed at 20 meter in Zeway

\begin{tabular}{|l|l|l|l|l|l|l|l|l|l|l|l|l|}
\hline Months & Jan & Feb & Mar & Apr & May & Jun & Jul & Aug & Sep & Oct & Nov & Dec \\
\hline 1989 & 2.7 & 2.9 & 1.9 & 1.8 & 2.9 & 3.3 & 3.4 & 2.8 & 2.1 & 3.1 & 4.2 & 3.0 \\
\hline 1990 & 1.8 & 3.0 & 2.8 & 4.4 & 5.3 & 4.4 & 4.3 & 3.2 & 4.2 & 3.7 & 3.9 & 3.6 \\
\hline 1992 & 3.0 & 2.9 & 3.7 & 3.0 & 4.0 & 4.5 & 3.4 & 3.0 & 3.7 & 3.4 & 3.3 & 3.7 \\
\hline 1993 & 3.0 & 3.1 & 2.5 & 2.5 & 3.6 & 3.2 & 3.3 & 2.5 & 2.7 & 2.9 & 2.6 & 3.5 \\
\hline 1995 & 3.0 & 3.5 & 3.4 & 2.8 & 4.3 & 4.2 & 4.0 & 3.0 & 2.9 & 3.6 & 4.0 & 2.8 \\
\hline 1996 & 2.5 & 2.5 & 2.2 & 2.3 & 3.4 & 3.2 & 2.6 & 2.1 & 2.7 & 2.6 & 2.4 & 2.2 \\
\hline 1997 & 3.7 & 3.1 & 2.9 & 3.0 & 3.1 & 3.4 & 2.8 & 2.3 & 3.0 & 2.8 & 2.7 & 2.5 \\
\hline 1998 & 2.0 & 2.2 & 2.1 & 3.5 & 5.0 & 4.7 & 4.5 & 2.6 & 3.0 & 4.6 & 4.4 & 5.0 \\
\hline 1999 & 4.6 & 3.9 & 4.5 & 3.4 & 4.1 & 3.8 & 3.2 & 2.6 & 2.3 & 3.1 & 2.8 & 2.5 \\
\hline 2000 & 2.6 & 2.6 & 2.3 & 1.6 & 2.6 & 2.3 & 2.5 & 1.6 & 2.1 & 2.3 & 2.1 & 3.4 \\
\hline 2003 & 4.0 & 3.5 & 0.0 & 3.3 & 4.3 & 3.9 & 3.8 & 3.2 & 3.9 & 4.0 & 3.7 & 2.8 \\
\hline 2004 & 3.7 & 3.3 & 2.7 & 4.2 & 5.4 & 4.2 & 3.8 & 3.2 & 4.2 & 4.5 & 3.7 & 0.0 \\
\hline
\end{tabular}

Figure 4.35 shows the Wind Rose based on 180 months data from January, 1989 - December, 2004 collected at 10 meters height and direction at 16 meters. This Wind Rose indicates that most of the time the wind direction was North-East. The annual average wind speed is $2.932 \mathrm{~m} / \mathrm{s}$ and the percentage of time when wind direction occurs towards North-East is above $60 \%$.

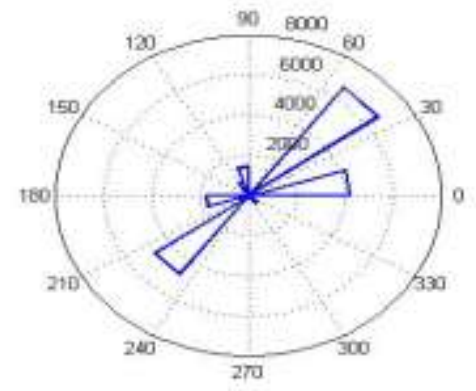

Fig.3.2 Wind rose At Zeway Station (10 meter height)

The choice of the wind generator is not done on the basis of the wind profile of the desired site because of no selection of power generation company were made in order to get their theoretical power coefficient. The aims were to obtain the maximum capacity factor for the installed generator, i.e. its maximum actual efficiency. This efficiency is measured in terms of equivalent duration (in hours) of the wind turbine operation at its nominal power.

\section{CONCLUSION}

Winds are generally stronger during the rainy season, which is from June until September. This study shows that mean wind speeds of 2.9 ms-1 are available in, Zeway, CRV which is suited for lifting water. The Best energy sector above $60 \%$ for harvesting the wind potential in, Zeway, CRV is in the North-East direction (400). There is a characteristic diurnal variation in Zeway such as mean wind speeds during 09:00 and 12:00 hours and peaks usually occur at 12:00.The maximum wind speed and wind power are received in a period of June up to September and moderate from October to May. Zeway has energy potential available with the maximum and minimum average wind speed respectively, $4.9 \mathrm{~m} / \mathrm{s}$ and $1.5 \mathrm{~m} / \mathrm{s}$ and average wind power density also varies with maximum and minimum values respectively, $68.6 \mathrm{w} / \mathrm{m} 2$ and $0.0 \mathrm{w} / \mathrm{m} 2$. Meteorological data, which is very essential to asses, construct, design and implement energy sustainability of the country, should be properly documented and archive for further study. The wind assessment has shown wind is very suitable for lifting water but the windmill should stand in the North-East direction during assembling. Feasibility checking by using wind power is further recommended. 


\section{ACKNOWLEDGEMENTS}

The author would like to thank Almighty God for his support and providence to this Paper fulfillment; Thank you above Father!!!!!!!!!!

\section{REFERENCES}

[1]. C.G.Justus, W.R. Hargraves and Ali Yalcin, Nationwide Assesment of potential output from wind powered generators, J. Appl.Meteor.Vol.15,No.7, pp.673-78 1976.

[2]. Dijk, H.J. van, Goedhart, P.D., Wind pumps for Irrigation, (Amersfoort: CWD, 1990)

[3]. F.W.Cole,Introduction to Meteorology, Wiley,N.Y (1970),

[4]. Johnson, G.L. (1978) 'Economic design of wind electric generators', IEEE Transactions on Power Apparatus and Systems, March/April, Vol. PAS-97, No. 2, pp. 554-562.

[5]. J.K.Kapur and H.C.Sexena, Mathematical Statistics, S.Chand and Company Ltd.Ram Nagar, New Delhi (1986)

[6]. Kristoferson, L.A., Bokalders, V., Renewable energy technologies, (Rugby: Intermediate Technology publications, 1991

[7]. Rai, G.D. (2000) 'Non conventional energy sources', Khanna Publishers, 4th Edition, New Delhi (India).

[8]. Sher Mohammad Nasir ,estimation of wind power potential in Packistan,Phd dissertation 1993, University of Balochistan Quetta

[9]. World Meteorological Organisation (WMO). 1994. Guide to meteorological instrument and observing practices. 4th Edition. WMO. No.8, TP.3, Geneva:Switzerland. 